\title{
Fraase laenamas: eestlaste ja soomlaste tõlkestrateegiaid
}

\author{
Pirkko Muikku-Werner \\ Ida-Soome Ülikooli emeriitprofessor \\ pirkko.muikku-werner@uef.fi
}

\begin{abstract}
Teesid: Eri keelte kõnekäänud ja fraasid võivad olla nii algupärased kui ka laenatud. Artiklis kirjeldatakse esmajoones laenatud fraase. Analüüs keskendub kahele peamisele tõlkestrateegiale: lähtekeelsele tekstile orienteeritud (assimileeritud) tõlkele ja sihtkeelsele tekstile orienteeritud (restitueerivale) tõlkele. Esimesel juhul on eesmärk lisada tõlgitud fraasile sihtkultuuri ja -keele elemente, et tähendus oleks paremini mõistetav. Teisel juhul püütakse säilitada lähtekeelsed jooned esialgsel kujul - räägitakse otse- või sõnasõnalisest tõlkest.

Artikli eesmärk on selgitada, kas eesti ja soome fraasid on laenatud ühisest allikast ning millised on tõlkeerinevused. Tutvustatakse ka mõningaid uuemaid soome keele fraase, vaadeldakse tänapäeva laene eesti ja soome keeles. ${ }^{1}$
\end{abstract}

Märksõnad: assimileerimine, eesti keel, fraasid, restitueerimine, soome keel, tõlkimine

\section{Fraasid: rahvuslik kapital või laenud?}

Matti Kuusi (1954: 70-71, 82) on tõdenud, et kõnekäänud väljendavad rahva iseloomu, andekust ja hinge. Isegi sama tähendusega kõnekäändudes võib olla eri keeltes nüansse, mis on omased rahvale ja ajastule ning edastavad maailmavaatelisi seisukohti. Nendest saadakse teavet riigi ajaloost, geograafiast, usust, kommetest, moraalist ja tunnetest. Kuna kõnekäänud kätkevad enamasti üldinimlikku tõdemust, on nende levimine igati loomulik. Sama suundumus iseloomustab oletatavasti ka fraase, ja neid ongi rohkesti laenatud.

Fraaside all peetakse silmas keelelisi tervikuid, mille kinnistunud struktuuris segunevad nii semantilised kui ka sümbolsuhted (Langacker 1987: 25). Nende tähendus ei selgu komponentide tähenduste liitmisel (Nunberg et al. 1994: 492-393). Kõnekäände ja fraase ei ole siinses ülevaateartiklis eraldi käsitletud, sest mõlemale on omane tähenduse piltlikkus. Samuti on neile tüüpiline üsna varieerumatu keelendamine. 
Läänemeresoome identiteeti on ühe elemendina alati kuulunud kontaktid Euroopaga. Eri keeleainese laenamine on tihedate kontaktide tulemus, mille tõendamine ei ole lihtne ega lünkadeta. Üldiselt ollakse seisukohal, et algselt romaani keeltes esinenud fraasid on laenatud eesti ja soome keelde eelkõige germaani keelte vahendusel (Muikku-Werner 2013: 300). Siinses artiklis käsitletavad eesti keele fraasid pärinevad Asta ja Katre Õimu Eesti fraseologismide elektroonilisest alussõnastikust (2011), soome keele fraasid Sakari Virkkuneni (1974) fraasisõnaraamatust ning Muikku-Werneri, Jantuse ja Kokko koostatud raamatust "Suurella sydämellä ihan sikana" (2008). Ülevaates esineb ka mõni näide kõnekäändude ja fraaside venekeelsetest vastetest.

Vanimad laenatud fraasid on pärit antiikkultuurist ja muinaslegendidest. Hiljem on neid laenatud kirjanduse, näiteks piibli ja läänemaiste klassikute vahendusel. Fraasid ei ole üle kandunud eri üksustena, vaid osana laiemast tervikust. Neis on talletunud mõned tähtsad ajaloosündmused, nagu Caesari sõjaretk Rubico ületamisega:

Damoklesschwert Damoklese mõõk Damokleen miekka далоклов меч;

Alea jacta est Liisk on langenud Arpa on heitetty.

Piibli piltlikkus on soosinud rohket idioomikasutust, mis on tõlgete abil laialt levima hakanud. Ka kuulsate kirjanike nagu Shakespeare’i repliigid on jõudnud oma algkodust vägagi kaugele:

zweischneidiges Schwert kahe teraga mõõk kaksiteräinen miekka обоюдоострый меч;

to be or not to be $\sim$ Sein oder Nichtsein $\sim$ olla või mitte olla $\sim$ ollako vai eikö olla быть или не быть.

Fraasilaenudes mainitud esemed ja nähtused võivad olla sihtmaal tundmatud. Siiski on need praeguseks osa ühisest läänelikust kultuuripärandist, mida nii eestlased kui ka soomlased jagavad (Muikku-Werner \& Penttilä 2014: 380; vt ka Piirainen 2012).

\section{Fraaside tõlkimise võimalusi}

Tõlkijal on sageli keeruline otsustada, kuidas kanda lähtekeele ja -kultuuri tunnusjooni üle sihtkeelde. Võib-olla aga jätta need üldse üle kandmata? Samas on maailma tunnetamise viisid suurel määral siiski universaalsed. Eriti Euroopa kontekstis leidub jagatud kogemust, mistõttu võib tõlkimine olla mõnikord 
üsna kerge. Ometi keelendatakse eri kultuurides samu tähelepanekuid tihti erinevalt ja seetõttu võib kuhjuda märkimisväärne hulk probleeme (Penttilä \& Muikku-Werner 2012: 122).

Siinses ülevaates on tehtud katse kirjeldada fraaside laenamist eesti ja soome keelde esmajoones saksa, rootsi või inglise keelest. Laenuandjakeele määratlemine ei ole alati üheselt võimalik, kuid see ei ole antud juhul probleem: fookuses on eestlaste ja soomlaste tõlkestrateegiad. On huvitav näha, kas sama fraas on tõlgitud mõlemasse keelde, kas tõlgetes võib märgata mingeid erinevusi jm. Lisaks käsitletakse artiklis lühidalt eesti ja soome keele potentsiaalseid laenusuhteid. Oletus seisneb selles, et tihenenud kultuuri-ja majanduskontaktid (soomlaste õppimine ja töötamine Eestis ning eestlaste õppimine ja töötamine Soomes) võiksid laenamist soodustada. Kuna autori eesti fraaside tundmine on tagasihoidlik, jääb rõhuasetus paraku Soomes ja eriti noorte hulgas soositud tänapäevaste fraaside võimalikule liikumisele Eestisse.

Lisaks fraasile kui laiemale mõistele vaadeldakse artiklis ka tõlkeidioome, mida siinses ülevaates määratletakse fraasidena, mis säilitavad piltlikkuse ka sihtkeeles. Lähtekeelse fraasi põhitähendus kandub üldiselt üle üsna hästi, selle sotsiaalsed jm konnotatsioonid võivad põhineda ajaloolistel viidetel, pragmaatilistel piirangutel, alliteratsioonil, riimil, huumoril. Neid võib pidada justnagu fraasi lisatähendusteks, mis võivad tuua arusaamatusi, sest kultuurierinevuste tundmine on keeruline. (Penttilä \& Muikku-Werner 2012: 124-125; Leppihalme 1994.) Siinses ülevaates käsitletakse põhitähenduse semantilist ekvivalentsi, kuid tähelepanu pööratakse ka eri keeltesse tõlgitud fraaside lisatähendustele jm erinevustele.

Tõlkestrateegiatest pakuvad võrdluseks eriti huvitava aluse kaks seisukohta: 1) lähtekeelsele tekstile orienteerumine ehk assimileerimine (ingl domesticating) ja 2) sihtkeelsele tekstile orienteerumine ehk restitueerimine (ingl foreignizing). Assimileerimise korral on küsimus võõrkeelse teksti etnotsentrilises reduktsioonis. Lähtekeele kultuurielemendid kohandatakse sihtkeele elementidele vastavaks või asendatakse nendega. Seevastu restitueerimist eelistav professionaal või hobitõlkija püüab säilitada lähtekeele ainese algsel kujul. Sel juhul ei põhjusta lähte- ja sihtkeele kultuuri- ja keeleerinevused algupärase teksti kohandamist (Venuti 1995: 20).

Soome keeles on mõnest kõnekäänust olemas paralleelsed versioonid, kus ühes kasutatud restitueerimist, teises assimileerimist. Näiteks mingil perioodil ei ole õun kõikides Soome piirkondades olnud tuntud ja nii on see vahetatud lähiümbruses leiduvate viljade nimetuste vastu. Sama eksootilised on skorpion ja mürkmadu, kes on asendatud sama hirmutavate kodumaiste loomadega hundi ja karuga: 
Ei omena kauas puusta putoa. $\rightarrow$ Ei käpy kauas kuusesta putoa (eesti käbi ei kuku kännust kaugele).

Paetessaan skorpionia hän joutui myrkkykäärmeen kitaan. $\rightarrow$ Läksi sutta pakoon, karhu tuli vastaan (eesti vihma käest räästa alla sattuma).

Mõnikord assimileerimine ebaõnnestub. Üks Aisopose valmidest räägib rebasest, kes solvununa hõrgutiste kättesaamatuse pärast väidab need olevat halvamaitselised. Saksa, eesti ja vene keeles on viinamarjad väidetavalt hapud:

Die Trauben sind sauer, sagte der Fuchs Viinamarjad on hapud, ütles rebane Виноград кисльй, сказала лиса.

Soome keeles on öeldu põhitähendus liigse assimileerimise tõttu kadunud: happamia sanoi kettu pihlajanmarjoista. Kui magus viinamari asendatakse hapu pihlakaga, muutub rebase algselt kibe märkus paikapidavaks tõdemuseks, mis väärtuse eitamise tõttu ei toimi pettumuse leevendamisviisina.

Huvitavaid otsuseid võidakse teha juba laenatavat kõnekäändu või fraasi valides. Näiteks saksa Adler fangen keine Fliegen 'kotkad ei püüa kärbseid' on ilmselt olnud liialt kõrgklassi keelekasutusele omane, et sobida võrdõiguslikkust toetava soome ühiskonna kujundkeele varamusse. Selle asemel on soome keeles kõlblikuks tunnistatud tõlge ingliskeelsest võrdsust rõhutavast ütlusest a cat may look at a king 'kasski vaatab kuningale silma'.

Fraaside ja muude kultuuriliselt keeruliste väljendite tõlkimise vajadust silmas pidades on Jan Pedersen (2005) loetlenud erinevaid strateegiaid (vt ka Leppihalme 1994; Nedergaard-Larsen 1993). Nende strateegiate kontiinumi äärtes paiknevad assimileerimine ja restitueerimine. Kuus allstrateegiat on säilitamine (retention) - lähtekeele kultuurispetsiifilist elementi ei asendata sihtkeelsega; eritlemine (specification); otsetõlge (direct translation); üldistamine (generalization); asendamine (substitution); kultuurispetsiifiliste elementide eemaldamine (omission). (Penttilä \& Muikku-Werner 2012: 125-126.)

Eestlaste ja soomlaste tõlkeid võrreldes selgub, et kasutatavamad on neli keskmist strateegiat. Eritlemine ja otsetõlge, mille allkategooriad on tõlkelaenud (calque translation) ja mugandatud otsetõlge (shifted direct translation), esindavad pigem restitueerimist, kuid üksikjuhtumite korral on nii sirgjooneline liigitus liiga jäik. Tõlkelaenudes kantakse kultuurilised vihjed sõna sõnalt üle lähtekeelest sihtkeelde, samas kui mugandatud otsetõlget võidakse interpreteerida isegi assimileerimisena, sest selle strateegia kasutaja võib asendada mõningaid kultuurispetsiifilisi elemente sihtkeelsetega. Assimileerimisstrateegiad on üheselt mõistetavalt üldistamine ja asendamine (jaguneb kultuuriliseks asenduseks ja parafraaside kasutamiseks). (Nt Vinay \& Darbelnet 1995: 32; Chesterman 1997: 94; Crystal 2008: 64.) 
Mõnikord seletub tõlkevastete vaheline erinevus keelestruktuuriga. Näiteks eesti ja soome keeles on inglise vääral viisil silitamise vahendamiseks olemas ilmekad liitsõnad, mida ka kasutatakse. Samas erinevad eesti ja soome keele infinitiivi vormid, mis tuleneb sõnaraamatute traditsioonist: eesti keeles kasutatakse verbi põhivormina $m a$-infinitiivi ja soome keeles $d a$-infinitiivi (Remes 2015: 151, 153):

rub someone's (fur) the wrong way gegen den Strich bürsten vastukarva silitama silittä̈̈ vastakarvaan.

Veereva kivi samblatuna püsimise fraas on kergesti tõlgendatav ilmeka visuaalse kujutluspildi tõttu. Eesti sammal/du/ma vastab tuletisena täpselt soome verbile sammal/tu/a -mõlemas lisatakse liide konsonantlõpulisele juurele, kuid seda moodust kasutatakse soome keeles harvem kui algselt vokaaltüvelist verbi sammal/oitu/a. (sammal/du/ma-tüüpi liidetest vt Remes 2015: 295.) Näiteks:

a rolling stone gathers no moss $\sim$ veerev kivi ei sammaldu $\sim$ vierivä kivi ei sammaloidu.

Järgnevas näites asendub inglise keele prepositsioonistruktuur tõlkes aglutineerivatele soome ja eesti keelele tüüpiliste käändelõppudega - eesti keeles kaasaütlevaga, mida kasutatakse ka instruktiivselt, ja soome keeles instruktiiviga. (Eesti kaasaütleva ja soome instruktiivi suhtest vt Remes 2015: 78.) Näiteks:

with long teeth pikkade hammastega pitkin hampain.

Mõnikord on erinevus lähte- ja sihtkeele vahel õhkõrn. Soome keel soosib sihtkeelena fraasikonstruktsioonis mitmust lähtekeelse ainsuse asemel:

do an X (do an Obama) tehdä X:t (tehdä väyryset).

Kuigi fraaside tõlkimiseks on arvukalt võimalusi, raskendab vaste leidmist fraasi tähenduse konstrueerimine terviku põhjal, mitte komponentide summana. Idioomi tõlkevastena ei ole algupärase väljendi seletamine tingimata õigustatud, kuigi see on üks variantidest.

Alljärgnevalt tutvustatakse lähemalt assimileerimisstrateegiat ja erinevaid restitueerimisstrateegia rakendamise võimalusi. 


\section{Assimileerimine}

Assimileerimise vajadus võib tuleneda sellest, et lähtekultuuris leidub elemente, mida sihtkultuuris sellisena ei esine või millega puututakse geograafilistel vm põhjustel harva kokku. Laenatud idioomifraasid võivad sisaldada ka mõisteid, millega sihtkeeles ei seostu samad nähtused kui lähtekeeles. Võõra teksti etnotsentrilisust on võimalik proovida vähendada eri võtetega ja tuttavat ainest lisades (Venuti 1995: 20; Penttilä \& Muikku-Werner 2012: 123).

Assimileerimise levinumaid allstrateegiaid on substitutsioon, mille korral spetsiifilised lähtekultuuri elemendid asendatakse sihtkeelsetega. See strateegia on väga lähedal mugandatud otsetõlke strateegiale, kuid terminina on substitutsioon laiem. Küsimus ei ole alati vaid selles, et tundmatud üksiksõnad vahetatakse tuttavate vastu. Juhul kui sihtkeeles on mõni varasem fraas, mis väljendab sama põhitähendust, siis kasutatakse seda.

Eestis ja Soomes ei ole haned peaaegu kunagi olnud kodulinnud ja üldse on Soome hanede populatsioon kasvanud alles 20. sajandi lõpul. Nii on kodune kana asendanud hane, kirjeldamaks külmast või hirmust põhjustatud reaktsiooni. Hane ja kana nahk on visuaalselt sarnane. Huvitaval kombel räägitakse vene keeles saksa ja inglise keele eeskujul just hane nahast:

Gänsehaut haben have goose pimples тело покрыто гусиной кожей $~ \boldsymbol{k a n a n a h k ~ o n ~ i h u l ~ ~ ~ o l l a ~ k a n a n l i h a l l a . ~}$

Kui nähtus esineb sihtkultuuris harva, siis ei seostu sellega sama palju ega samasuguseid assotsiatsioone kui lähtekultuuris ning sõnasõnaline tõlge ei vahenda fraasi kõiki sotsiaalseid ja ajaloolisi viiteid. Üks erinevusi põhjustavatest seikadest on kontekst. Kuigi nii eestlased kui ka soomlased joovad teed, ei ole tegemist samasuguse rituaaliga kui briti kultuuris, kus teejoomisel on probleemide lahendamise ja harmoonia säilitamise lisatähendus. Nii kirjeldab torm teetassis ka ühiskonna põhiväärtuste segipaiskamist. Fraasil torm veeklaasis on enam-vähem sama põhitähendus, kuid konnotatsioonid puuduvad: olukorda ei tunnetata kuigi problemaatilisena. (Penttilä \& Muikku-Werner 2012: 129-130.) Huvitav on see, et ilmselt saksakeelsest fraasist eeskuju võtnud Soome ei ole asendanud vett seal levinud kohviga. Ka Venemaal, tuntud teejoojamaana, on torm veeklaasis. Tuleb siiski tähele panna, et nüüdisajal kasvanud inglise keele mõju tõttu võib nii eesti kui ka soome keeles torm olla ka teeklaasis, kuid siiski mitte teetassis. Näiteks:

storm in a teacup Sturm in Wasserglas torm veeklaasis myrsky vesilasissa буря в стакане воды, vrd storm teeklaasis myrsky teelasissa. 
Omaette asendamise liik on parafraas. Kui saksa- ja eestikeelses idioomis on keel vesti peal, siis soomlasel on keel vöö all. Mõlemal juhul räägitakse suurest kiirustamisest:

die Zunge auf der Weste keel vesti peal kieli vyön alla.

Ka rumaluse kirjeldamisega kaasneb vaatenurga vahetudes paralleelne keelendamine: kruvid ei ole kinni või alles, need võivad olla lahti või lõdvad, eesti keeles aga logisevad. Inglise keeles on kruvide asemel nipsukivid (not have all one's marbles), mis on briti kultuuri osana rohkem mõeldav kui teistes kultuurides. Näiteks:

eine Schraube locker haben $\sim$ kruvid logisevad $\sim$ kaikki ruuvit eivät ole tallella (ruuvit löysällä) у него винтиков в голове не хватает 'tal ei jätku peas kruvisid'.

Mõnel juhul on raske ütelda, mis on põhjustanud erinevate mõistete valiku. Väljend kissa säkissä on teatud mõttes loogilisem, kui taustal on kujutluspilt petmiskatsest: müüja on ostetud sea asemel pistnud koti täiteks väärtusetu kassipoja. Jääb mõistatuseks, miks nii eesti kui ka soome keeles on kassi asemel siga. Näiteks:

die Katze im Sack kaufen купить кота в мешке 'kassi kotis ostma' põrsast kotis ostma ostaa sika säkissä.

Ka kahe tegevuse samaaegsuse kirjeldamiseks peetakse eri keeltes sobivaks eri loomi. Saksa ja inglise keeles on tapetavaks lind, vene keeles jänes, eesti ja soome keeles rahuldutakse väiksemõõduliste kärbestega. Näiteks:

zwei Vögel mit einem Stein töten $\sim$ kill two birds with one stone yбumb сразу двух зайцев tapma kaks kärbest ühe hoobiga tappaa kaksi kärpästä samalla iskulla.

Mõnikord on tõlgetes kasutatud eri kaashüponüüme. Näiteks on keelendamiseks valitud käe kaks erinevat osa - peopesa või sõrmed:

(to know) like my palm (tundma) nagu oma peopesa (tuntea) kuin omat sormensa знать что-либо как свои пять пальцев 'tundma midagi nagu oma viit sõrme’.

Assimileerimisel ei ole alati küsimus vaid selles, et viited konkreetsetele võõrastele nähtustele asendatakse tuttavatega, sest muutused võivad keskenduda väljendi laadile. Fraase on võimalik vürtsitada huumoriga, taotletakse esteetiliselt nauditavat leidlikku keelendamist. Tõlkija võib seda teadlikult suunata. 
Selline tavakasutusest erinev sõnastamine lisab mõjukust, mõningal juhul isegi poeetilisust. (Vt ka Penttilä \& Muikku-Werner 2012: 132.)

Teinekord annab tõlkele vürtsi sündmuse esitamine intensiivsuse suurenemise etappidena. Näiteks hullumise äärel olijat ootab ees protsessi kulmineerumine:

\section{drive someone mad ajaa hulluuden partaalle 'hulluks ajama'}

Ingliskeelse idioomi avatud ussipurgist ei sünni väga hirmutavaid assotsiatsioone. Saksa ja soome fraasides lahti päästetud saatan muudab olukorra selgelt ohtlikumaks. Antud juhul on tõenäoliselt tegemist inglise ja saksa idioomi iseseisva paralleelvariandiga, mitte laenusuhtega:

open a can of worms den Teufel los lassen päästää piru irti.

Intensiivsust rõhutatakse ka teemasse puutuvate sõnade arvu suurendamisega. Näiteks eestikeelsesse fraasi on lisatud tähed ja rõhutatakse ka sihtkohta alla (maha):

das Blaue vom Himmel versprechen promise someone the moon lubab mulle kuu (ja tähed) taevast alla (maha) tuua luvata kuu taivaalta.

Ekspressiivsuse laiendamise vahendina võidakse soosida erinevat sõnavalikut. Juba kogu poolest vastandlikud sääsk (või kärbes) ja elevant loovad tugeva visuaalse kujutluspildi, mis siiski ei ole soomlastele olnud piisav. Lisaintensiivsust on taotletud häälikulisest kooskõlast kärpänen ja härkänen. Väljendi erandlikkust rõhutab asjaolu, et deminutiiv ei tundu seoses sõnaga härkä 'härg' just väga loomulik:

aus einer Mücke einen Elefanten machen делать из лухи слона kärbsest elevanti tegema tehdä kärpäsestä härkänen.

Nii eesti kui ka soome keeles on algriim üks tüüpilisemaid ilmekuse lisamise viise, mistõttu võib pidada selle kasutamist assimileerimiseks (kaasneb tuttavlik tunne). Lisaks rahvaluulele kasutatakse seda võtet ka paljudes uuemates tekstiliikides. Järgnevas näites tuleb esile tugev alliteratsiooni mõju. Tüüpiline väikelind varblane on asendatud harvem esineva pü̈̈ga algustähe tõttu. Soome keeles esinebki selles fraasis pea alati arhailise varjundiga pivo:

lieber den Spatz in der Hand als die Taube auf dem Dach parem pü̈̈ peos kui kümme põllul parempi pyy pivossa kuin kymmenen oksalla. 
Mõistagi ei ole algriim võõras teisteski keeltes. Järgnev näide osutab, kuidas alliteratsiooni saavutamiseks muudetakse keelendamise viisi. Samas tuleb siiski meeles pidada, et laenusuhet ei ole võimalik tõestada:

Cat got your tongue? Veikö kissa kielen? 'Kas kass võttis (viis) keele ära?'

Üks tõlkestrateegiatest põhineb sellel, et lähtekeele üsna üldisel tasemel olev mõiste, sageli hüperonüüm, asendatakse sihtkeele spetsiifilise väljendiga, nt hüponüümiga. Nähtust võidakse esitleda täpsemalt mõne detaili abil nagu järgnevates eestikeelsetes versioonides. Selline strateegia lisab fraasile piltlikkust. (Vt nt Pedersen 2005: 4; Penttilä \& Muikku-Werner 2012: 130-131.) Näiteks:

die Fäden in der Hand haben niidiotsad käes langat käsissä;

passen wie die Faust aufs Auge sobib nagu rusikas silmaauku sopii kuin nyrkki silmään.

Täpsustamine muudab huvitavamaks mõned fraasid, mis rõhutavad saavutatud eesmärgi väärtust. Piltlikkus luuakse loomade abil ja lindudegi rühmas esineb mitmeid variante. Näiteks inglise ja soome keeles kaalutakse vahet tulemusliku tegutsemise ja võimalike soovide vahel lindude hulgaga. Soomlased tugevdavad ebaturvalise lahenduse kõlbmatust: kui inglise keeles väljendavad vale valikut kaks lindu põõsas, siis soome keeles on vaja selleks lausa kümmet tuvi oksal:

a bird in the hand is worth two in the bush $\sim$ parempi pyy pivossa kuin kymmenen oksalla.

Saksa, eesti ja vene keeles tagavad õnnestumise kätte saadud argipäevane varblane või sinitihane, kuid toredamana näiva tuvi või ööbiku pärast ei ole mõtet hädaldada:

lieber den Spatz in der Hand als die Taube auf dem Dach parem varblane peоs kui tuvi katusel синица в руках лучше соловья в лесу parempi sinitiainen kourassa kuin satakieli metsässä.

Samasugust täpsustust võib märgata idioomifraasides, mis viitavad olukorra tõukamisele halvenemise suunas. Inglise keeles räägitakse sel juhul kütusest, saksa, eesti ja vene keeles ôlist. Ka soome bensiin on võrreldes ingliskeelse väljendiga spetsiifilisem. Näiteks:

add fuel to the flames Öl ins Feuer gießen olli tulle valama подлить ласла в огонь kaаtаa bensaa liekkeihin. 


\section{Restitueerimine}

Restitueermisstrateegiat kasutav tõlkija laenab fraasi enam-vähem sõna-sõnalt, nii et ka idioomi struktuur säilib. Selle strateegia rakendaja kannab lähtekeelest üle elemente ja mõisteid, millele tuginedes sihtkultuuri esindaja ei ole võimeline fraasi tähendusest aru saama. Seetõttu tuleb tõlkijal peale üksiksõnadele vastete leidmist arvesse võtta ka väljendi taustal olevat kultuurikonteksti, millel lähtekeele kujundlikkus eriilmeliselt põhineb. (Bassnett \& Lefevere 2001; Fan 2007: 222; Muikku-Werner \& Penttilä 2014: 380.) Just sellest tulenevate arusaamisprobleemide tõttu ei ole sõnasõnalist tõlkimist peetud kuigi heaks strateegiaks, vaid pigem markeeritud alternatiiviks.

Kõikidel juhtudel võõrast tuttavaga siiski ei asendata. Eespool mainitud terviktsitaadid vanematest kirjalikest allikatest ja mõned ajaloosündmused või ütlused siirduvad sihtkeelde otsetõlgetena. Paljud väärtustavad pühasid tekste võimalikult täpsete tõlkevastetega, sest truudust algtekstile peetakse sobivaks selle üleloomuliku olemuse tõttu (Serban 2006: 51).

Ka argisemad piltlikud väljendid võivad olla laenatud paljudesse keeltesse:

like a greased lightning wie ein geölter Blitz nagu õlitatud välk

kuin rasvattu salama с быстротой молнии 'välgukiirusel';

bark up the wrong tree $\sim$ den falschen Baum anbellen $\sim$ haukuma vale puu all haukkua väärää puuta;

shed crocodile tears $\sim$ Krokodilentränen gießen $\sim$ krokodillipisaraid valama vuodattaa krokotiilin kyyneleitä проливать крокодиловь слезьь.

Eespool toodud fraasid on eakad. Esimene neist on vägagi piltlik, tähendusest arusaamist toetab tähelepanek välgusähvatusest. Ka teise puhul viitab jahikoera eksitus saagita jäämisele (vale puu all haukumine), mis samuti mõistetav. Seevastu krokodillipisaraid pole nähtud, selles on midagi kummalist. Pisarad voolavad näiteks süües, sest kida avanemine põhjustab ilmselt survet pisarakanalitele. Siit ei ilmne aga ei kahetsustunnet ega teeseldud kurbust. Kuna idioomi tähendust üldiselt siiski teatakse, siis ei vaevuta taustateadmiste üle arutlema.

Tänapäeval võib kummaliste idioomidega kokku puutuda nii võõrkeelsetes tekstides kui ka suulistes suhtlusolukordades, kust need on välja nopitud ning eesti ja soome keelde tõlgitud. Kõigepealt võib idioom tulla suulisse keelekasutusse, nt siseringis seoses mõne harrastusega. Inglise keel tähendab tänapäeval modernset rahvusvahelisust ja selle elemente kandub vähemalt 
soome keelde üle otse või mugandatuna vägagi erinevate kontaktide kaudu (Leppänen \& Nikula 2008: 21).

Järgnevad idioomid on nopitud eesti ja soome keeles kirjutatud tekstidest, nii et tegu ei ole ajutise otsetõlkega, vaid ehtsate tõlkelaenudega, mis on tulnud eesti ja soome keelde hiljuti ning mille ingliskeelsed vasted on laialt levinud (Penttilä \& Muikku-Werner 2012: 134). Kuna uudislaenude kasutus on alles värske, siis on lisatud ka sihtkeelne lausekontekst:

(not) sharpest pencil in box - tavaliselt eitavas lauses 'mitte kõige tublim': (mitte) kõige teravam pliiats pinalis (ei) penaalin terävin kynä [eesti keeles kohtab ka vähem otsetõlkelist varianti (mitte) kõige kirkam kriit karbis].

when pigs fly 'mingi asi on võimatu': Enne hakkavad sead lendama, kui tema lõpetab tapeedi kiskumise. Enoni totesi kylän miehille, että ennen sika lentää kuin Tainalla on ajokortti [varem oli kasutusel ka variant lehmät lentävät].

piece of cake 'lihtne asi': Matemaatika on koogitükk! Autokoulu on pala kakkua.

Järgnevas lauses on fraas ahvid seljas pärit Postimehes ilmunud Jussi Tupamäki tsitaadist, nii et antud juhul on tõlkelaen tulnud esmajoones soome ja sealt eesti keelde:

have a monkey on one's back 'raskusi olema': Meil oli momente visata rohkem väravaid, aga mõnedel mängijatel on endiselt "ahvid seljas". Jotain on tehtävä myös silloin, kun pelaajalla on apina selässä.

Otsetõlgeteni on jõutud ka juhuslikult - vastavalt olukorrale, sageli harrastustõlkijate vahendatuna. Selle arvelt võib laenuala veelgi suureneda. Tegu on uudislaenudega, mis olemas soome keeles, kuid puuduvad eesti keeles ja vastupidi. Näiteks:

need something like a hole in the head 'ei vaja üldse': Tarvitsen uutta kompaktikameraa yhtä paljon kuin reikää päähän.

small potatoes 'väikesed probleemid': Jopa tämän jälkeen Suomi on pieniä perunoita globaalin datasiirron voluumeissa.

On vägagi võimalik, et mõned eespool toodud fraasidest jäävadki osale lugejatest võõraks, sest tähenduse mõistmine toimub sageli mõistes kajastatud kogemuse põhjal. Näiteks kui ahv seostub millegi positiivsega, siis ei sünni kujutlus raskustest kuigi lihtsalt. Kui kontekst ei toeta piisavalt vahendatud 
sõnumit, jääb ka ahvi roll ähmaseks. Spordireportaažide lugejatel selliseid probleeme loomulikult ei teki.

Eestlaste ja soomlaste tihenenud kontaktid tekitavad küsimuse, kas see soodustab sugulaskeelte vahel uute fraaside ülekannet. Kuna algupärased eesti idioomid ei ole käesoleva artikli autorile tuttavad, lähtub järgnev soome keelest.

Mõnede aastate eest lisandus soome noorte keelekasutusse hulgaliselt sikaalgulisi sõnu, et intensiivistada öeldut: sikamakee, sikahyvä, sikarikas. Siin pole sõnal siga negatiivset varjundit, mis varem on olnud tüüpiline: mies on täysi sika (Õim, K. et al. 2013: 440). Näiteks:

Sikasiisti seinäkello lastenhuoneeseen. Eile oli sigavinge reede õhtu.

Eesti noorte keelde on sika-algulised sõnad üle võetud, sigavinge omakeelne variant oleks ülivinge, st eriti vinge.

Keelega mängimine ja humoorikas väljenduslaad on kõnekäändudele omane tunnusjoon, sama traditsioon jätkub ka mõnede fraaside puhul (Kuusi 1954: 158-161; Punttila 2004: 38; Penttilä \& Muikku-Werner 2012: 135). Näiteks ihan sikana tähendab 'eriti palju'. Väljend ise ei ole eesti keelde otse üle võetud, kuid sika-algulised sõnad sisaldavad seda tähendust.

Inglise keeles kasutatakse tavalisest tagasihoidlikuma vaimse võimekuse kirjeldamiseks fraasi $\boldsymbol{a}$ few beers short of a six-pack. Rootsi, eesti ja soome keeles on sama olukorda väljendatud järgmiselt:

han har inte alla flingor i paketet 'tal ei ole kõik maisihelbed pakis' pole kõik kodus ei ole kaikki kotona.

Fraasi päritolu kohta andmed puuduvad. Idioomi konstruktsioonist ei ole kaikki $x$ :t $y$ :ssä on saanud noorte hulgas levinud ja produktiivne mall (Kortelainen 2011: 93). Kõnekeeles tähistab see natukse lihtsameelset või psüühiliselt haiget inimest. Sarnaste fraasimuganduste populaarsus põhineb nende humoorikusel. Kasutatud aines pärineb väga erinevatest elusituatsioonidest. Sama malli järgivaid eestikeelseid fraase internetiotsinguga esile ei tulnud. Näiteks:

ei ole kaikki kaljat korissa kaikki murot kulhossa kaikki muumit laaksossa kaikki pöllöt tornissa kaikki kupit kaapissa kaikki inkkarit veneessä.

Otsetõlkega taotletakse mõnikord erimõju, mida assimileerimine ei võimaldaks. Samuti kasutatakse seda juhul, kui sihtkeeles vaste puudub. Lisaks võib asendamine sihtkeelse fraasiga anda algselt soovitud sõnumile väära tähenduse. Praegune innukas laenamine sõnasõnaliste tõlgetena peegeldab muutust, milles inglise keelel on keeletegelikkusele suur mõju. Vanem põlvkond ei pruugi inglise keelt sedavõrd osata, et mõista idiomaatikat, mis on keeruline isegi 
edasijõudnud keeleõppijale. Praegustel kooliõpilastel on vähem probleeme. (Muikku-Werner \& Penttilä 2014: 399.)

Suhtluse õnnestumise seisukohalt on mõistagi arukas suhelda väljendite abil, mida lugeja või vestluskaaslane oletatavasti mõistab. Mõnede laenatud fraaside tähenduse selgitamisel aitavad kaasa teatud harrastused. Näiteks fraasi apina selässä tõlgendamisel on toeks spordislängi tundmine. Tegelikult pärinebki suurem osa laene spordi ja popkultuuri valdkonnast. Teatud ringkondadele meeldib teatud hulk fraase, mille kasutamine eristab neid teistest keelekasutajate rühmadest, mis lisab ühisvaimu. Nii tugevdatakse subkultuuri, mille kujundajana on suur mõju inglise keelel ja kultuuril. Sõnasõnaliste tõlgete kasvu tingib osaliselt ka see, et laenamine ei ole enam professionaalsete tõlkijate pärusmaa. (Muikku-Werner \& Penttilä 2014: 400.)

Olgugi et assimileerimise puudumine võib takistada ülekantud fraaside mõistmist, ei ole põhjust unustada, et uued tõlkelaenud rikastavad sihtkeelt ühel või teisel moel. Ebatavaliselt kõlaval fraasil on kahtlemata uudsuse võlu. (Penttilä \& Muikku-Werner 2012: 135.) Leidub teisigi motiive, nt mõne mõjuvõimsaks peetud rühma liikmelisuse taotlemine. Mia Passi (1990) järgi soovivad võõra ainese laenajad rõhutada oma haritust ja keeleoskust, tahavad hoobelda, äratada tähelepanu või rõhutada oma huumorimeelt.

\section{Järeldusi}

Analüüsides erinevate keelte fraase, saadakse selgust, kuidas inimesed maailma tunnetavad. Samas ei saa vaid fraaside põhjal kuigi palju öelda, sest suurem osa neist on laenud ja omakeelset päritolu väljendite mõtet saab erinevalt keelendada.

Fraaside laenamisest, eriti aga tõlkimisest tulenevaid otseseid probleeme keele- ja kultuuripiiridel on raske jälgida. Mõistagi tuleb tõlkijal ette probleeme, kui ta proovib asendada lähtekeele idioomi samasisulise sihtkeele idioomiga. Assimileerimine viib äärmuslikel juhtudel (nt rebane ja pihlakad) väära tõlgenduseni. Uusimad sõnasõnalised tõlked põhjustavad omakorda arusaamisraskusi ennekõike nendele kuulajatele ja lugejatele, kes ei kuulu fraasi kasutajate hulka.

Osa fraasidest kõlab arhailiselt. Paljude meelest kuuluvadki fraasid eakate meeste keelekasutusse või on pateetiliste peokõnede ehe. Kui koostasime fraasisõnaraamatut (Muikku-Werner et al. 2008), siis märkasime, et osa varem kirja pandud idioomidest ei ole enam internetiainestikus kasutusel. Sakari Virkkuse (1974) sõnaraamatus leiduvatest fraasidest on interneti keelekasutusest raske leida värskeid näiteid. Samas on mõned kõige uuematest 
idioomidest osutunud sedavõrd elujõulisteks, et neist on saanud konstruktsiooni mugandamise tulemusena produktiivsed mallid. Teisalt aga hakkavad ennast ammendama ihan sikana ja muud sika-ühendid ning kaikki intiaanit veneessätüüpi fraasid.

Eesti ja soome keelde laenatud idioomides on palju ühist. Mõlemas keeles on säilinud tavaliselt põhitähendus, kuid varjundeid ja lisatähendusi on konstrueeritud veidi erineval viisil. Näiteks kasutatakse mõlemas keeles intensiivistamist ja kõrgendamist, kuid mitte tingimata samades idioomides ega samamoodi keelendatuna.

Eriti vanade idioomide tõlgetes esineb erinevaid assimileerivaid elemente, mis lihtsustavad arusaamist. Nii eesti kui ka soome keeles on soositud võõra ainese asendamine tuttavaga, väljendit on täpsustatud, selle keelendamise viisi on tõhustatud, lisatud isegi poeetilist ainest ja humoorikust. Selline jätkuv idioomide viimistlemine tekitab mingil määral ka uusi tähendusnüansse, mistõttu tänased kujutluspildid ei ole päris samasugused kui varasemad. (Vt Penttiä \& Muikku-Werner 2012: 135.)

Mõnikord säilitatakse eesti keeles ilmselt saksa keelest laenatud vorm, samal ajal kui soomlased teevad teistsuguseid otsuseid. Näiteks eesti keeles on peos varblane, soome keeles pü̈̈ esmajoones algriimi tõttu. Mingil põhjusel on nii soomlased kui ka eestlased asendanud kotis ostetud kassi (die Katze im Sack kaufen) seaga. See asendus viib põhja alt idioomi sündi mõjutanud kujutletavalt petmisteemalt. Mõistatuseks jääb, kas küsimus võiks olla vigases laenus, võib-olla pole mõistetud põhitähenduse tausta?

Assimileerimine tundub laenajatele meeldivat. Siiski on restitueerimiselgi toetajaid. Põhitähenduse täpne vahendamine on sageli olnud elementide sõnasõnalise tõlkimise põhjus. Eriti on kardetud teha muutusi seoses piiblitekstidega. Tänapäeval julgetakse paranenud keeleoskuse tõttu taas kasutada otsetõlget. Tõlgendamisprobleeme ei sünni juhul, kui laenuidioomi kontekst on piisavalt piltlik ja selle tähendus argikogemuse põhjal tuletatav. Osa idioomidest ei seostu rahvusliku kultuuriga, vaid põhineb globaalsetel nähtustel, mis hõlbustab sõnumi siirdumist (universaalsetest mõistemetafooridest vt Õim, K. et al. 2013: 437; Muikku-Werner \& Penttlä 2014: 401). Mida rohkem on ühist teadmust, seda väiksem on assimileerimise tarve.

Tõlkijal on sageli raske otsustada, millist strateegiat rakendades võib jõuda parima tulemuseni. Siin on oluline mõista idioomi mõistestamist lähtekeeles. Kui aga potentsiaalne sihtrühm ei valda lähtekeelt, siis on assimileerimise hea külg see, et võõras aines võidakse asendada. Restitueerimine aga toob kaasa lisaks täpsusele ka uut huvitavat ainest (vt Penttilä \& Muikku-Werner 2011: 262). 
Mitteametlikus keelekasutuses on sõnasõnaline tõlge osaliselt harrastustõlkide töö tulemus. Kui laenude vahendaja on noorsugu, siis võib võõrlaenu eelistamise põhjus olla selle uudsus, veetlus ja erilisus. Ingliskeelseid fraase tutvustades tahetakse näidata oma keeleoskust (vt nt Muikku-Werner \& Penttilä 2014: 400). Kuigi eesti ja soome noortel on omavahel tihedad kontaktid, paistab nii, et tihtipeale pole soomlaste soositud laenud eesti keeles kodunenud. Selle väite tõestamine nõuab laiema ainestiku süstemaatilist analüüsi. Edaspidi oleks huvitav välja selgitada, kas ja mil määral on Eestis elavate soomlaste argikõnesse siirdunud eestikeelseid fraase. On muidugi võimalik, et vähemalt nii eesti kui ka soome ametlik keelekasutus eelistab prestiižika inglise keele fraasivaramut, et asendada omakeelset kulunud idiomaatikat värskemaga.

\section{Tõlkinud Annekatrin Kaivapalu}

\section{Kommentaarid}

1 Autor tänab asjakohaste kommentaaride eest Hannu Remest ja Maria-Magdalena Jürvetsoni.

\section{Kirjandus}

Bassnet, Susan \& Lefevere, André 2001. Constructing Cultures: Essays on Literary Translation. Shanghai: Shanghai Foreign Language Education Press 34.

Chesterman, Andrew 1997. Memes of Translation: The Spread of Ideas in Translation Theory. Amsterdam/Philadelphia: John Benjamins.

Crystal, David 2008. A dictionary of linguistics and phonetics. 6. kd. Malden: Blackwell. Fan, Min 2007. Cultural issues in Chinese idioms translation. Perspectives: Studies in Translatology 15 (4), lk 215-229 (doi: 10.1080/13670050802401445).

Kortelainen, Kristiina 2011. Ei ole kaikki muumit laaksossa. Tutkimus suomen kielen idiomikonstruktion produktiivisuudesta. Julkaisematon pro gradu - tutkielma. Turku: Turun yliopisto, kieli- ja käännöstieteiden laitos.

Kuusi, Matti 1954. Sananlaskut ja puheenparret. Helsinki: Suomalaisen Kirjallisuuden Seura.

Langacker, Ronald W. 1987. Foundations of Cognitive Grammar I. Theoretical Prerequisites. Stanford: Stanford University Press.

Leppihalme, Ritva 1994. Culture Bumps: On the Translation of Allusions. Helsinki: University of Helsinki, English Department Studies 2. 
Leppänen, Sirpa \& Nikula, Tarja 2008. Johdanto. Leppänen, Sirpa \& Nikula, Tarja \& Kääntä, Leila (toim). Kolmas kotimainen: Lähikuvia englannin käytöstä Suomessa. Helsinki: Suomalaisen Kirjallisuuden Seura, lk 7-18.

Nedergaard-Larsen, Birgit 1993. Culture-bound problems in subtitling. Perspectives: Studies in Translatology 1993, 2, lk 207-242 (doi: 10.1080/0907676X.1993.9961214).

Muikku-Werner, Pirkko 2013. Viel eigenständiges und ein wenig Lehngut: Wie das finnische Wesen sich in Phraseologismen darstellt. Järventausta, Marja \& Pantermöller, Marko (toim). Finnische Sprache, Literatur und Kultur im deutschsprachigen Raum Suomen kieli, kirjallisuus ja kulttuuri saksankielisellä alueella. Veröffentlichungen der Societas Uralo-Altaica, lk 299-311.

Muikku-Werner, Pirkko \& Jantunen, Jarmo Harri \& Kokko, Ossi 2008. Suurella sydämellä ihan sikana: Suomen kielen kuvaileva fraasisanakirja. Jyväskylä: Gummerus.

Muikku-Werner, Pirkko \& Penttilä, Esa 2014. Idiomit osana kielikontakteja: Lainaidiomien merkityksen päättelyä. Virittäjä 3, lk 372-407.

Nunberg, Geoffrey \& Sag, Ivan A. \& Wasow, Thomas 1994. Idioms. Language 70 (3), lk 491-538 (lingo.stanford.edu/sag/papers/idioms.pdf).

Passi, Mia 1990. Anglicisms in Columns. Master's thesis. Joensuu: University of Joensuu, Department of Translation Studies.

Pedersen, Jan 2005. How is culture rendered in subtitles? MuTra 2005 - Challenges of Multidimensional Translation: Conference Proceedings (http://www.euroconferences. info/proceedings/2005_Proceedings/2005_Pedersen_Jan.pdf - 12. oktoober 2017).

Penttilä, Esa \& Muikku-Werner, Pirkko 2011. English gatecrashers in Finnish: directly translated English idioms as novelties of Finnish. Kujamäki, Pekka, Kolehmainen, Leena, Penttilä, Esa \& Kemppanen, Hannu (toim). Beyond Borders: Translations Moving Languages, Literatures and Cultures. Berlin: Frank \& Timme, lk 247-265.

Penttilä, Esa \& Muikku-Werner, Pirkko 2012. Domestication and foreignization figurative idiom translation. Jänis, Marja, Kemppanen, Hannu \& Belikova, Alexandra (toim). Domestication and Foreignisation in Translation Studies. Berlin: Frank \& Timme, lk 121-138.

Penttilä, Esa \& Muikku-Werner, Pirkko 2014. Understanding translated vs. nontranslated figurative idioms: Results of a questionnaire survey. Paulasto, Heli \& Meriläinen, Lea \& Riionheimo, Helka \& Kok, Maria (toim). Language Contacts at the Crossroads of Disciplines. Newcastle upon Tyne: Cambridge Scholars Publishing, lk 161-189.

Piirainen, Elisabeth 2012. Widespread Idioms in Europe and beyond: Toward a Lexicon of Figurative Units. New York: Peter Lang.

Punttila, Matti 2004. Sananparsien uuskäyttöä. Kielikello 2.38 (http://www.kielikello. fi/index.php?mid=2\&pid=11\&aid=1508 -12 . oktoober 2017).

Remes, Hannu 2015. Viron kielioppi. Helsinki: Finn Lectura. 
Serban, Adriana 2006. Translation and genre: Sacred texts. Encyclopedia of Language and Linguistics. Amsterdam: Elsevier, lk 47-53 (doi: 10.1016/B0-08-044854-2/00486-7).

Venuti, Lawrence 1995. The Translator's Invisibility: A History of Translation. London/ New York: Routledge.

Vinay, Jean-Paul \& Darbelnet, Jean 1995 [1958]. Comparative Stylistics of French and English: A Methodology for Translation. Sager, Juan C. \& Hamel, M.-J. (tlk ja toim). Amsterdam/Philadelphia: John Benjamins.

Virkkunen, Sakari 1974. Suomalainen fraasisanakirja. Helsinki: Otava.

Õim, Asta \& Õim, Katre 2011. Eesti fraseologismide elektrooniline alussõnastik - FES (http://www.folklore.ee/justkui/sonastik - 12. oktoober 2017).

Õim, Katre \& Õim, Asta \& Muikku-Werner, Pirkko 2013. Uudne metafoorne keelend: Kas laen või diakroonilise arengu tulemus? Lähivõrdlusi. Lähivertailuja 23, lk 428-458.

\title{
Summary
}

\section{Loan idiom phrases: Estonian and Finnish translation strategies}

\author{
Pirkko Muikku-Werner \\ University of Eastern Finland \\ pirkko.muikku-werner@uef.fi
}

Keywords: Estonian, Finnish, domestication, foreignisation, idiomatic phrases, translation

Even rather similar proverbs and idiomatic phrases can have national nuances. They reflect the view of life and cultural reality typical for the nation in question. They give information about history, religion, manners, ethics, feelings, etc., of a country. However, the interaction between neighbours is a part of culture, and has contributed to cultural exchange. Because the ideas appearing in proverbs and phrases are in many respects universal, their globalisation happens naturally.

Idiomatic phrases are challenging to translate because their meaning is not compositionally derived from their parts. This article demonstrates and compares the strategies that have been used for Estonian and Finnish (TL) in idiomatic phrase translations. The source languages (SL) are German and English.

Two main translation strategies are presented: domesticating and foreignising. Domestication refers to the strategy in which the translator tries to reduce potential SLspecific elements by substituting them with corresponding TL-specific cultural elements. When using foreignisation as a strategy, translators refrain from making any changes, although cultural elements are divergent in the SL and TL, and they are retained in translations as close to the original as possible. 
The meaning of the idiom can be divided into two: the core meaning and additional meaning. Using this dichotomy helps, above all, to describe what kind of changes take place in the domesticating process. Idiomatic phrases carry a package of cultural values associated with the SL, and it is not an easy task to discover which culture-specific and language-specific features, and how, are translatable into the TL. In addition, idiomatic phrases can contain various more or less "poetic" elements, like uncommon words, exceptional word order, alliteration or rhyme. Transferring all these qualities to the TL is difficult but would contribute to maintaining the original expressive power, which is an important component of the idiomatic phrase in its native language.

The results indicate that domestication strategies have a very important role in translation. Estonian and Finnish translators favour, for instance, substitution. They also add some expressive constituents like alliteration. Very old loan idioms are not domesticated. Particularly older people prefer established translations, even though they can encompass culturally unfamiliar elements. An interesting new phenomenon is direct, word-for-word translation. This kind of foreignising may be due to the speakers' wish to show their English skills or their expertise. The use of this strategy stresses something special, like belonging to a certain in-group.

There are some differences between Estonian and Finnish translations. Sometimes the Finnish translators advance further in the direction of the target language and culture than the Estonian ones. However, this solution seems to be arbitrary, not regular. Finns are keen on using a new calque translation which not necessarily adds to the intelligibility of the text. Some typically Finnish idiomatic phrases, popular especially among the young people, have not crossed the ocean. It would be very interesting to find out if the Finns living or studying in Estonia have absorbed local idioms. 